Chapter 52

\title{
THE DIKES OF THE POLDERS IN THE IJSSELMER
}

\author{
M. Klasema \\ C.H. de Jong \\ senior engineers \\ Service of the Zuiderzee Works, \\ The Hague, Netherlands
}

\begin{abstract}
Since the circumstances on the IJsselmeer will change by the reclamation works, observations on the present lake cannot direct$1 \mathrm{y}$ be used for the determination of the cross-sections of the dikes protecting the reclaimed land. The method of obtaining the necessary data (water level, wave attack) is discussed, as well as the determination of the design level.

A reasoned description is given of a typical cross-section of a polderdike.
\end{abstract}

\section{INTRODUCTION}

The Zulderzeeproject comprises the enclosure of the Zuiderzee, a large shallow estuary (mean depth $3,5 \mathrm{~m}$ ) of the North Sea, and partial reclamation of the enclosed area (fig. 1). The enclosing dam separating the Zuiderzee from the North Sea was completed in 1932. By building this dam the safety as well as the water management of the hinterland has been improved. The reclamation started In 1928 and 1 still in full progress. When completed, $2300 \mathrm{~km}^{2}$ of arable land, divided over 5 polders, will be added to the landarea of the Netherlands. The reclaimed land is situated 4 to $5 \mathrm{~m}$ below the mean level of the IJsselmeer, as the remaining fresh water lake within the enclosed area is called. In view of the water management of the hinterland the minimum size of the lake has to be at least $1200 \mathrm{~km}^{2}$.

The economic value of a polder of $500 \mathrm{~km}^{2}$ is more than a thousand million guilders and 50000 or more people will live in it. Failure of the polder dike would mean an inundation during several months and would cause severe damage to all objects inside the polder. So the dikes protecting the polders against the water of the IJsselmeer have to meet with very high requirements of safety. On the other hand the construction cost of the dikes amounts to 4000 to 5000 guilders for each hectare reclaimed land, that is about 30 percent of the total reclamation cost. Therefore a careful study of the dike dimensions is necessary.

Failure of a polderdike could be due to overtopping of the crest by the waterlevel or by waves, to direct wave attack or to loss of stability. For the determination of the cross-section of the dike the variations in the waterlevel have to be known, as 
well as the dimensions of the waves. Observations in nature on the open Zuiderzee or on the present large lake cannot directly be used, since circumstances on the final lake will be different from those on the former Zuiderzee or on the large lake. In the next chapters will be discussed how the necessary data for the final lake are obtalned, after which a reasoned description is given of a typical cross section of the surrounding dikes of the new polders.

\section{DEFINING FACTORS}

The defining factors for the cross section of a dike are schematically shown in a longitudinal profile over the lake (f1g. 2). The actual water level in front of the dike depends on the volume $V$ of the water in the lake and the denivellation $D$ of the water surface due to wind. The uprush $U$ of the waves against the slope of the dike depends on the wave dimensions (especially the wave height H) near the dike, on the direction of the wave attack with regard to the direction of the dike, and on the crosssection of the dike. The importance of these factors varies for the different points along the dike. In some points the windeffect ( $D$ and $U$ ) is dominant. In other less exposed areas the volume $V$ is determinant.

\section{THE WATER VOLUME OF THE LAKE}

A certain mean lake level corresponds with a certain volume V. The variations with time of the mean lake level are due to natural circumstances - the supply to the lake surpassing the natural discharging capacity of the sluices in the enclosing dam or to levelregulations in view of storage of water for periods of drought. Based on observations during the period 1932 - 1959, and taking into account possible future changes in water management, the mean lake level has been computed with an electronic computer for every day in that period assuming that the lake would have had its final size. The solid line $V 30$ in fig. 3 denotes the varlation of the mean lake level during the severe flood period of january 1948, as observed on the lake with an area of $3000 \mathrm{~km}^{2}$. The dashed line $V 12$ represents the computed course of the level on the final lake of $1200 \mathrm{~km}^{2}$. The desired lake level in wintertime, the wet period, is $40 \mathrm{~cm}$ below the dutch reference datum N.A.P. (= approximately mean sea level). During floods long periods of exceedance of the desired level may occur, as is also shown in fig. 3. This makes it possible that a high lake level coincides with a gale with a strong windeffect.

THE WINDEFFECT

The windeffect consists of 2 phenomena: waves and denivellation of the water surface. Investigation of the denivellation and 
THE DIKES OF THE POLDERS IN THE IJSSELMER

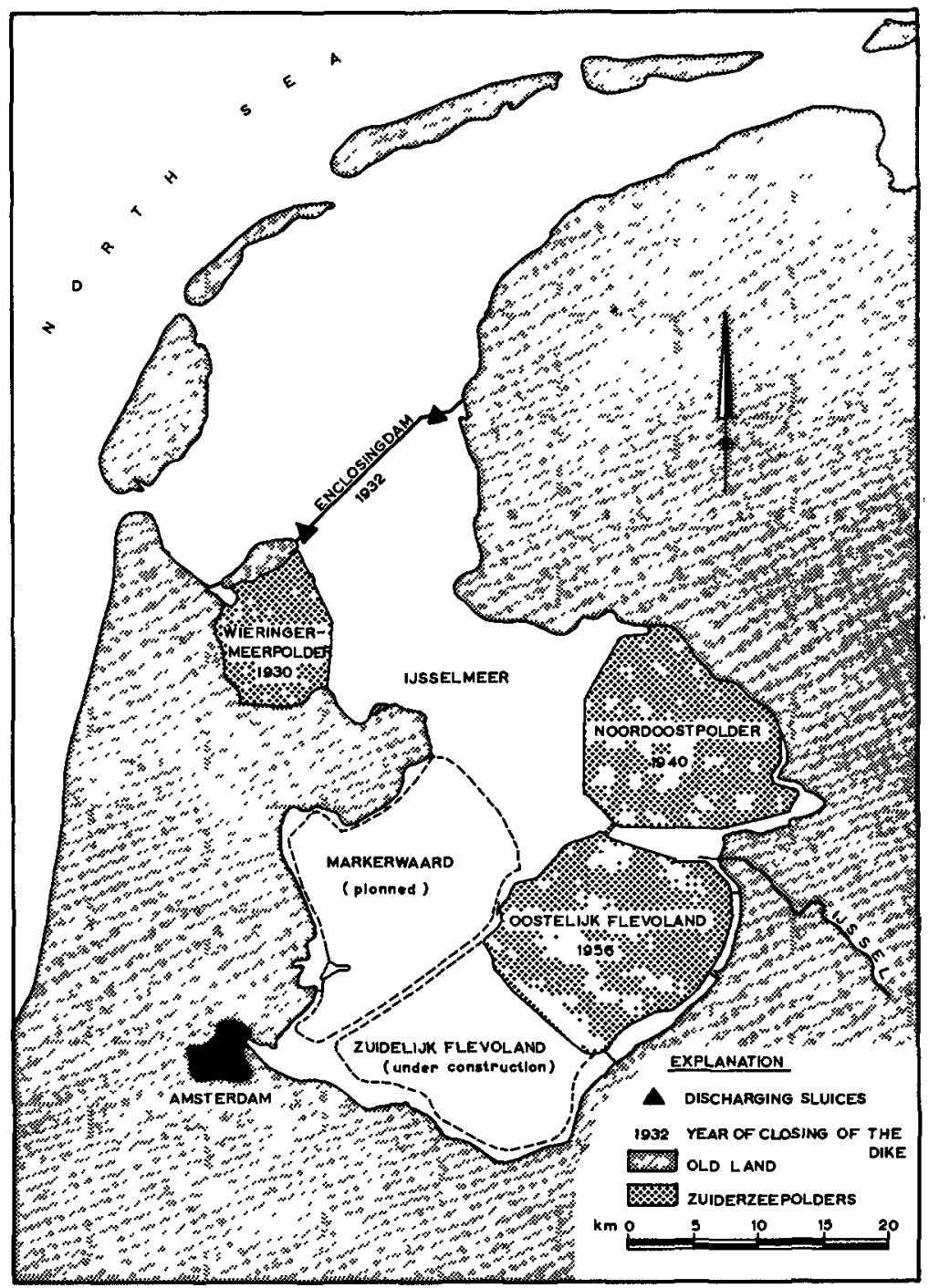

Fig. 1. The Zuiderzee project.

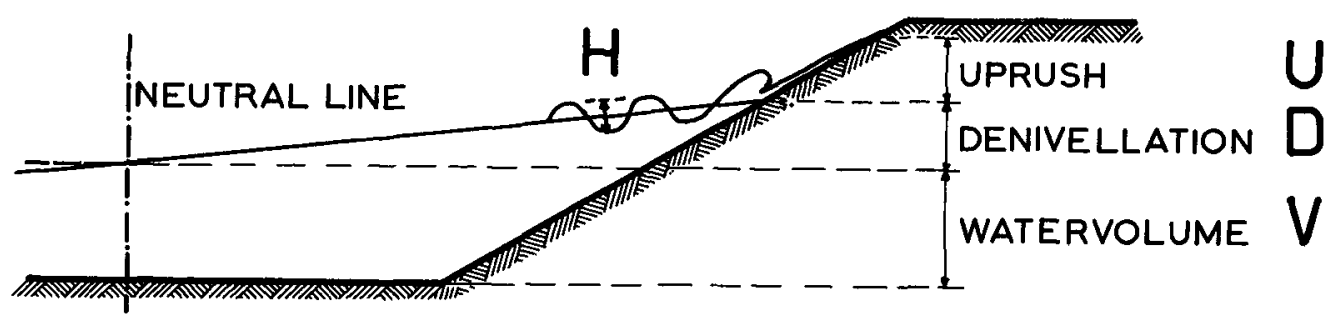

Fig. 2. Schematic longitudinal profile with defining factors . 
the wind on the present lake has learned that after about one hour a stationary condition is reached, which can be calculated with the formula for windeffect in a closed channel (Lorentz 1926).

$$
z=\frac{\alpha v^{2} 1 \cos \varphi}{\alpha}
$$

where

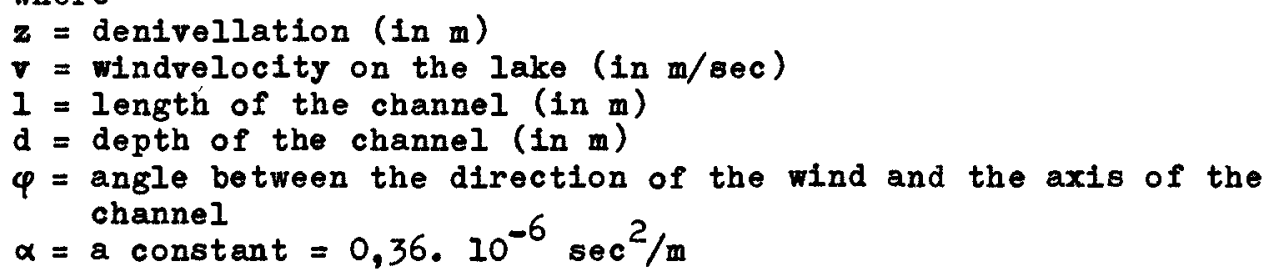

With the ald of this formula the denivellation on the final lake has been calculated for different velocities and directions of wind; the results are marked down on maps. Fig. 4 shows an example of such a map; it gives the denivellation caused by a north-westerly wind of $25 \mathrm{~m} / \mathrm{sec}$, having a frequency of exeedance of 0,04 .

For the determination of the height and length of shallow water waves on the lake Thijsses diagram (Thijsse 1948) has been used up till nor. Of late ware heights have been observed on the lake with a floating wave recorder (Roest 1960). The wave dimensions on the lake are calculated for the same winds as the denivellation and are also marked down on the abovementioned maps (fig. 4).

Then the ware uprush on the dike is determined by using the results of modelinvestigations in the Hydraulic Laboratory at Delft (Wassing 1957). To verify the modelinvestigation a number of wave-uprush gauges has been installed on the existing dikes.

\section{DESIGN CRITERION}

After the calculation of the values on the final lake of each of the defining factors separately, they have to be combined to determine the dimensions of the dike.

At the reclamation of the Noordoostpolder in the years 1936 1942 frequencles have not yet been considered. The usual procedure up till then was that the highest known water level was chosen as design level. In concordance herewith the dimensions of the polder dike have been determined by applying a combination of the most 


\section{THE DIKES OF THE POLDERS IN THE IJSSELMER}

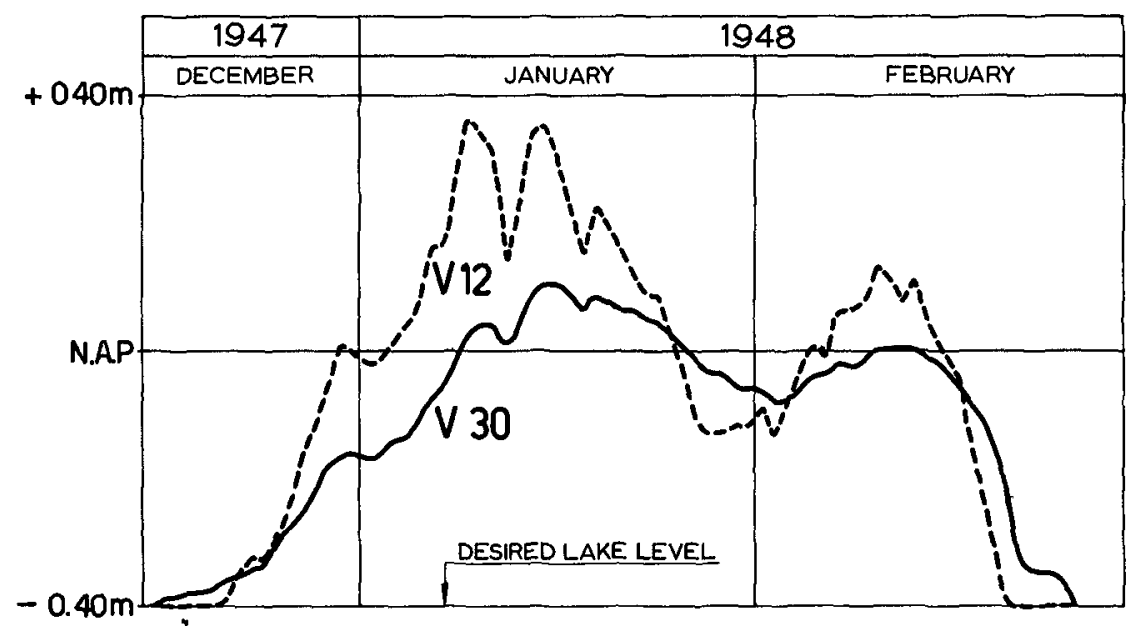

Fig. 3. Mean lake level during the severe flood period of January 1948 .

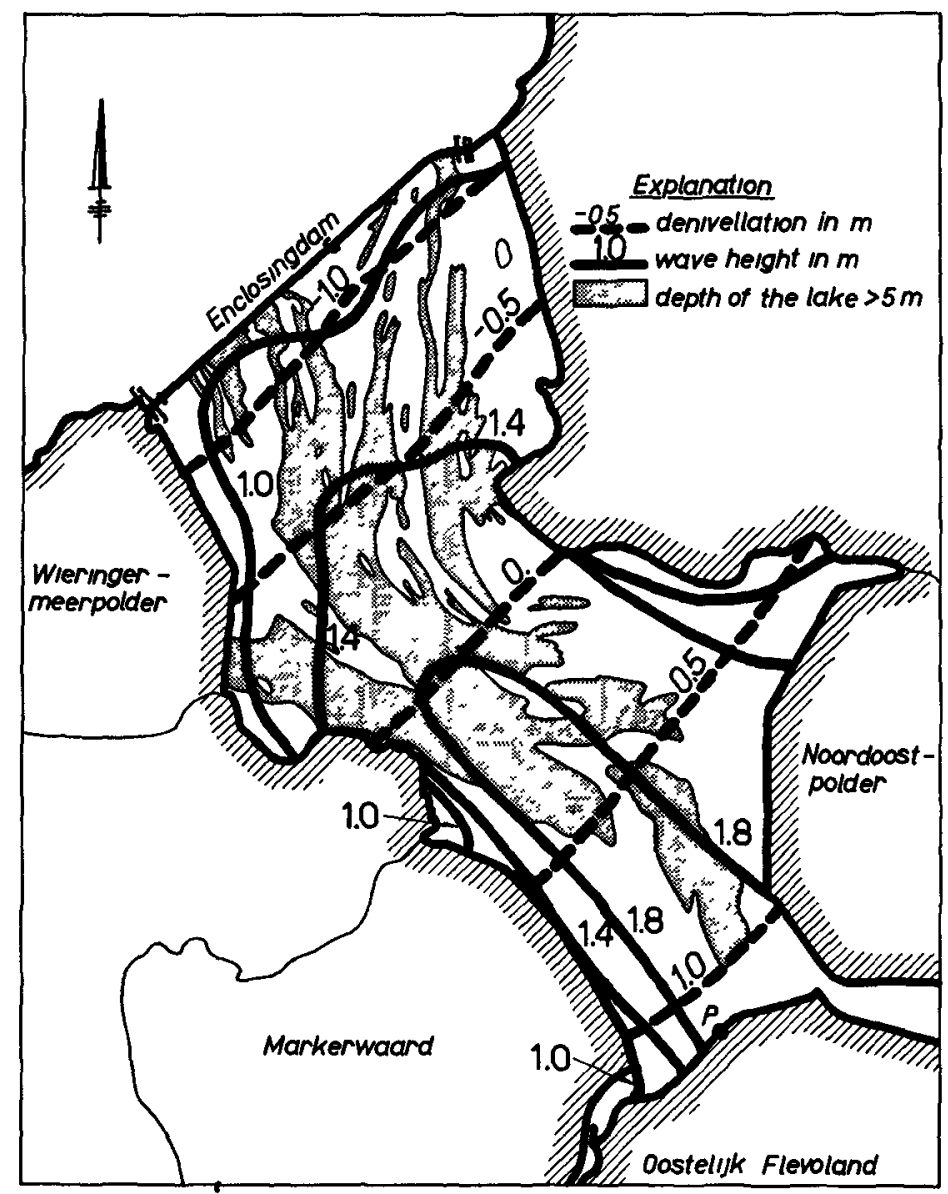

Fig. 4. Map indicating denivellation and wave height at a northwestern wind of $25 \mathrm{~m} / \mathrm{sec}$. 
unfarourable conditions of water supply to the lake, limited discharge and windeffect on the considered part of the dike, which had ever been observed separately until then. Of course these values have been converted to conditions prevailing on the final lake. Calculation afterwards of the frequencies of overtopping showed that application of this methes resulted in different chances of overtopping and consequently of failure for different points of the dike.

At the polder Oostelijk Flevoland, the reclamation of which started in 1950, frequency curves of the actual water level in front of the dike and of wave uprush - both measured with regard to N.A.P. - have been constructed for each part of the dike. The frequency curves have been defined in the way, demonstrated for the point $P$ (fig. 4) with the aid of fig. 5, in which the scale of heights is arithmetic and that of frequencies (= mean chances of exceedance in a year) logarithmic. In this diagram solid lines indicate the calculated frequency curves of the mean lake level $V$ and of the windeffect $D+U$ ( $U$ being the uprush which is exceeded with a frequency of 0,02 ). It is evident that at low frequencies the curves are straight lines on semi-logarithmic paper. For this reason the curres, if necessary, have been extrapolated by straight lines. The frequency curves of windeffect and mean lake level have been combined to a frequency curve for the top of the wave uprush with regard to N.A.P., whereby the dependance of windeffect and lake level has been taken into account. The top of the $2 \%$ wave uprush with a frequency of 0,001 has been chosen as a criterion for the height of the dike.

The actual water level in front of the dike is also an important factor. The frequency curve of $D+V$ with regard to N.A.P. has been determined in a similar way as for the wave uprush by combining the frequency curves of $D$ and $V$. Because overtopping of the dike by the water level causes a more dangerous situation than that by the wave uprush, a frequency of 0,0001 has been selected as the criterion in this case.

As a result, and in contrast to the dike of the Noordoostpolder, the dike of Oostelijk Flevoland bounded by the final IJssellake has the same strength everywhere. A weak point in the calculation is howerer the ill-known dependance of windeffect and mean lake level.

For the remaining polders the following procedure is considered. Based on observations on the large IJssellake it is possible to construct for the final situation for a period of 30 years a series of data concerning mean lake level, actual waterlevel and actual waterlevel + wave uprush for different points along the dike, and hence to derive a frequency distribution of these phenomenae. To get the design level these curves have to be 


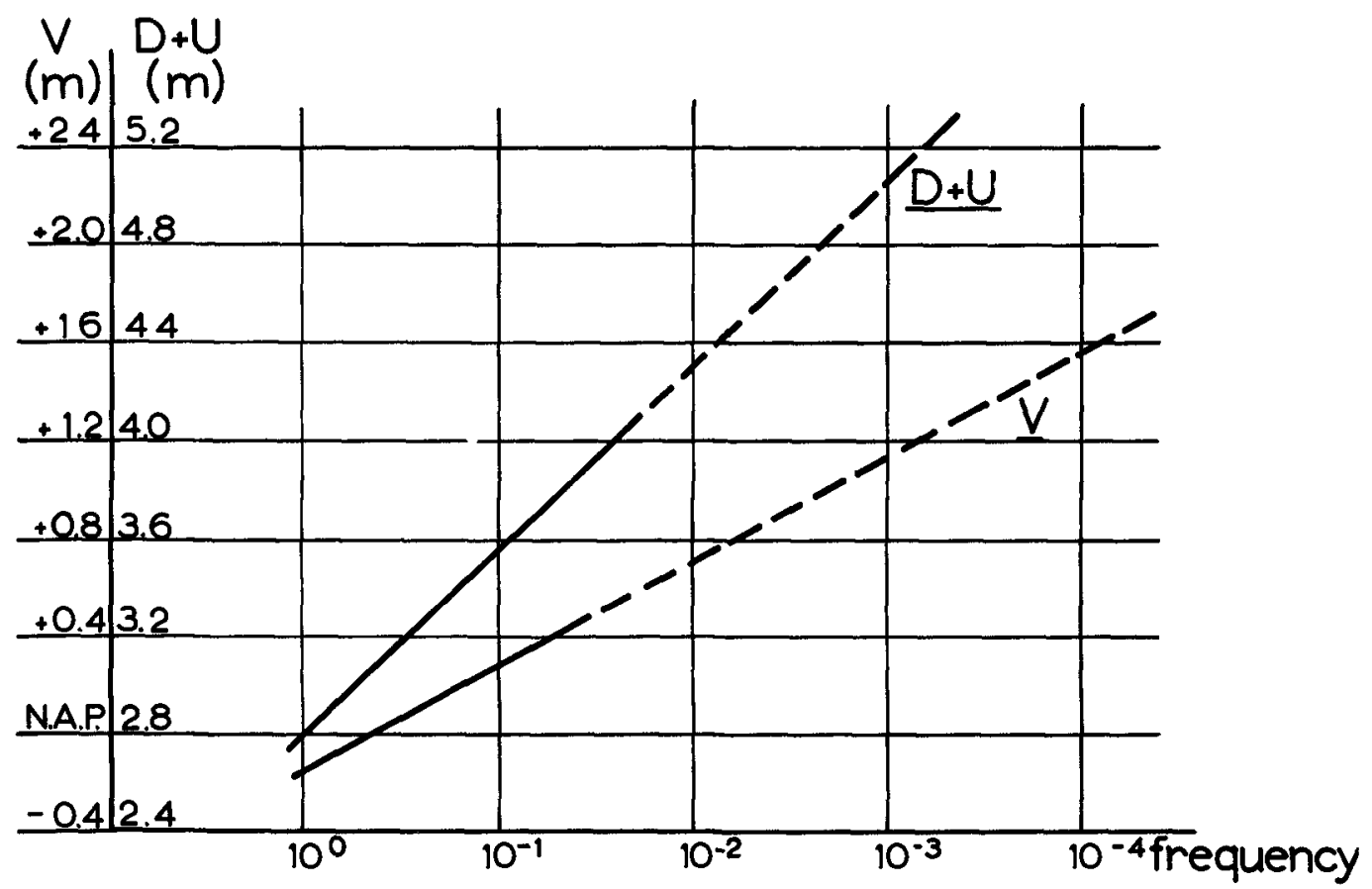

Fig. 5. Frequence curves of mean lake level on the final lake and of wind effect $(D+U)$ in point $P$.

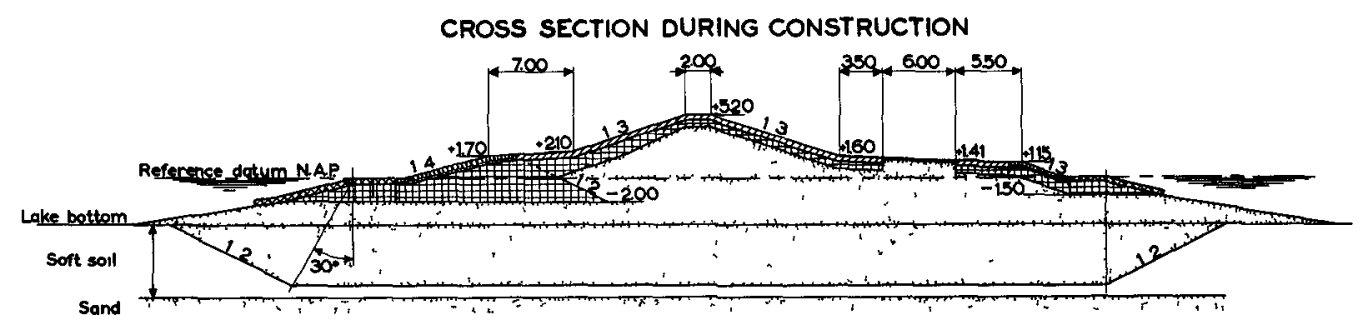

FINAL CROSS SECTION

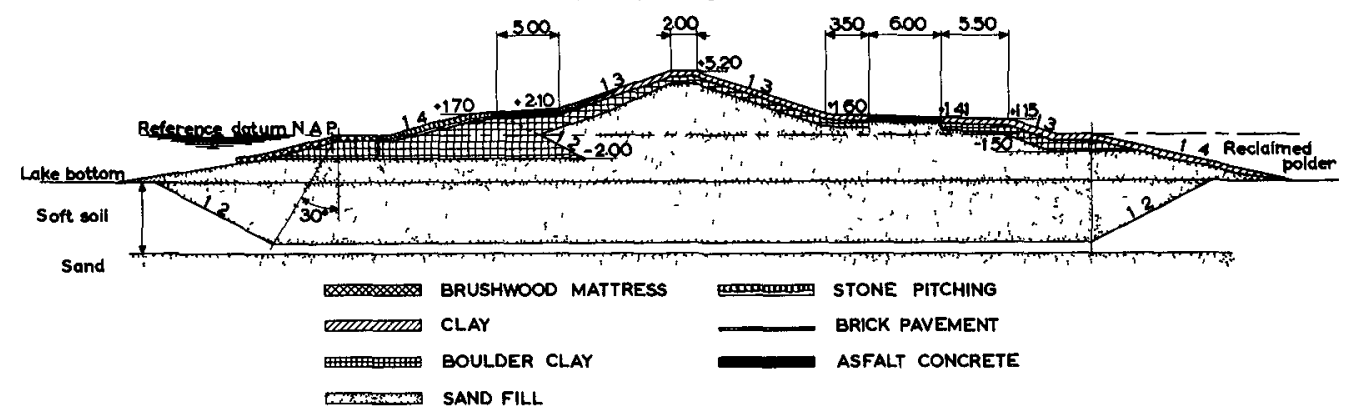

Fig. 6. Typical cross section of polderdike. 
extrapolated. In this way the difficulty of combining the separate frequency curves of lake level and windeffect is met.

Another difficulty remains. The design level can be reached by a combination of a low lake level and a strong windeffect, but also by a combination of a high lake level and a weak windeffect. The chance of failure is not the same in these cases, whereas at the determination of the frequency curves these cases have got the same weight. For that reason it seems appropriate to check the so achieved dike dimensions by choosing a very rare value for one of the defining factors and a moderate value for the other one. The first check is then a flood with a frequency of occurrence of for instance 0,0001 . Calculate the corresponding mean lake level, assuming a limited discharging possibility of the lake and combine this lake level with a moderate storm. The other check is an extreme wind on the lake combined with a moderate exceedance of the lake level.

The frequency of these checks is only very roughly known, but the same applies to a design level obtained by extrapolating a frequency curve based on observations during a period of less than a century to frequencies of 0,001 or even 0,0001 . The importance of frequency considerations lies mainly in the possibility of achieving an aequivalent safety for the different low lying parts of the country.

\section{DESIGN OF CROSS SECTION}

\section{STABILITY AND SETTLEMENT}

Since one of the original aims of the Zuiderzeeworks was the reclamation of large areas of arable land, the new polders are projected in those parts of the former Zuiderzee where the toplayers of the soil consist of fertile clay. These claylayers which are locally alternated by layers of peat have a limited bearing strength, which would not be sufficient to carry the heavy load of the dikes without endangering the stability of the construction. Furthermore these thick and very soft layers would give rise to a considerable settlement of the dike, which in itself would be undesirable in view of the requirements concerning dike height etc, discussed hereafter.

In order to warrant a stable dike of more or less constant height the greater part of the soft layers in the proposed dikeline is removed and replaced by sand before building the dike. The width of the excavation depends on the width of, the dike - which in itself is dependant again on its height and on the gradient of the side slopes - and on the depth of the excavation. The width will have to increase with depth in order to meet the spreading of stress in the bottom. 
Since the thickness of the soft layers is limited it would be obvious to remove them to their total depth, thus excluding any danger for slidings and reduce settlement to a minimum. The clay and peat layers are, however, normally underlain by strata of sand reaching to depths of some hundreds of meters and containing artesian water. It is therefore undesirable to make a short circuit between these deep sand strata and the sandbody of the dike and consequently with the polder. This could enhance the seepage to the polder to an intolerable amount in regard of the pump capacity and it could endanger the stability of the inner slopes of the dike.

It has become normal practice therefore not to remove the soft layers to their total depth but to leave a layer of appr.1.00m thickness in its place on top of the deep sand strata. This layer will be compacted by the load of the dike and will constitute a nearly impervious separation between the sandbody of the dike and the deep sand strata. The settlement of the dike, due to compaction of this layer, will normally not exceed 30 to 35 centimeters and this can be easily overcome by giving some extra height to the dike during construction.

\section{COMPOSITION OF DIKES}

Since sand can be borrowed from the bottom of the IJsselmeer at a suitable depth, generally in the immediate vicinity of the works, it is by far the cheapest building material that can be obtained and consequently the main body of the polderdikes will consist of sand. This body of sand has, however, to be protected against currents and wave attacks, measures have to be taken to limit percolation and even those parts of the cross section that are not exposed to these phenomena will have to be covered in order to forestall erosion by wind and rain.

It is considered that beyond a depth of N.A.P. $-2 \mathrm{~m}$ (which is appr. half of the depth in front of the dikes, built in the deepest part of the area to be reclaimed) sand will be stablo without any covering layer, provided the angle of the slope is well below the angle of natural repose under water. The uncovered sandslopes are normally built with a gradient of $1: 6$.

Above this depth a more resistant material has to be used. In the IJsselmeer-area boulderclay is applied. This is a heavy glacial loam, which crops out of the bottom of the northern part of the IJsselmeer in several places, for instance near the former island of Urk, where it can be dredged. This material is practically impervious, it is temporarily current and wave resistant, it has a high cohesian and a high shearing strength. It is therefore an excellent dikebuilding material and it is used not only as a permanent impervious covering layer between the sandbody and the protective layers of brushwood or stones but as well as a temporary 
wave resistant protection which enables a running working method without any inadmissable risks.

For the ultimate situation the boulder clay has to be protected against wave attacks and erosion. The part below mean lake level is protected by brushwood matresses, loaded with rip-rap, the slope above this level is partly covered with a stone pitching, consisting mainly of columnar basalt blocks, and partly by a grasscover on a layer of fresh clay. The clay can be borrowed from the IJsselmeer near the works, brushwood is borrowed from the outer marches of the Dutch rivers and estuaries; the stones for rip-rap and stone pitching form the only material to be imported from abroad.

\section{SHAPE OF CROSS SECTION}

Under normal conditions of water supply and discharge the water level on the lake fluctuates around the referencedatum N.A.P. The part of the dike between some decimeters below and above N.A.P. will therefore be exposed to the daily wave-attack. A horizontal berm on this level, which is already necessary to fix the brushwood matresses on their place, will at the same time serve as an energy dissipating berm. For this reason this berm is made rather wide and it is covered with heavy rip-rap (120 - $240 \mathrm{~kg})$, neatly placed and locked up by two rows of wooden piles.

Another berm has been designed on the height of the design lake level, which, as stated before, will differ for different points in the lake. This berm serves to partly dissipate the energy of the waves, breaking on the slope of the dike and so deminishing the height of the wave uprush along the upper slope. The width of the berm to be fully effective should be at least $1 / 4$ to $1 / 3$ of the length of the waves occurring under the assumed conditions.

The gradient of the slopes and the weight of the stones used for the stone pitching are closely interrelated. A steeper slope requires heavier stones, a more gentle slope results in a larger area to be covered with stones but the length and weight of single stones can be less. The angle to be chosen is therefore partly a question of economy.

The minimum angle of the slope, however, has to be decided on stability considerations. It is found that for dikes exposed to the heaviest wave attacks to be expected on the IJsselmeer the gradient of the slope should not exceed $I: 4$ and for less exposed dikes $1: 3$.

The gradient of the slopes on the polderside of the dikes in their final state is entirely decided on considerations of stability, assuming the crest being overtopped by waves or the waterlevel on the lakeside rising to an extreme height.

\section{SLOPE PROTECTION}

The strength of the slope protection can be adapted to the power of the wave attack, which will change with height. The strongest protection will have to be made on that part of the slope that will be exposed to the strongest wave attack, i.e. approximately on the height of the design level, just underneath 
the high outerberm, where the breaking waves at the design level hit the slope. Beneath and above this strip, which may be rather wide, the strength of the protecting layer can decrease proport1onaliy to the decrease of the wave force.

In accordance with this, lighter and cheaper materials are used on the slope above the berm and part of this slope, that will only under extreme conditions be reached by the tops of a small number of waves, has got merily a grass protection.

The slopes on the polderside of the dike have to be protected temporarily against wave attack, because during construction the future polder is still part of the lake. The protection of the lower part of these slopes consists therefore temporarily of a stone or concrete pitching, which is composed in such a way that after the polder has been drained, the materials can be used for protection of the outer slope above the berm. The uppermost part of the inner slope and the crest of the dike are protected by a grass cover on a layer of fresh clay.

\section{REQUIREMENTS FOR TRAFFIC}

During the first years of reclamation, when there are still no road connections through the polder, it is essential that all points of the circumference of the polder can be reached by road in order to be able to start the reclamation works from several different points. To this end a road has been designed on the dike, mostly on the crest, that has to be widened then, sometimes, especially at the higher parts of the dikes, on a berm.

As far as these roads are built on dikes bounded by the IJssellake in its final shape and size, they should have a closed road surface in view of the possibility of overtopping of the dike. Since, however,initial settlement of the dike may differ rather strongly from one point to another, a temporary brick pavement is applied during construction. After a couple of years, when the greater part of the settlement of the subsoil has taken place and the road foundation has been compacted by traffic, this brick pavement will be replaced by a road surface of asphalt concrete.

\section{REFERENCES}

Lorentz, H.A. Verslag van de staatscommissie inzake hoogere waterstanden tijdens storm, als gevolg van de afsluiting van de Zuiderzee. 1926.

Thijsse, J.Th. Dimensions of wind-generated waves. Assembly I. U.G.G. , Oslo,1948.

Roest, P.W. Wave recording on the IJsselmeer. VIIth Conference on Coastal Engineering. The Hague, 1960.

Wassing, F. Modelinvestigation on wave run-up carried out in the Netherlands during the past twenty years. VIth Conference on Coastal Engineering. Florida, 1957. 